\title{
Trichostatin A reverses epithelial-mesenchymal transition and attenuates invasion and migration in MCF-7 breast cancer cells
}

\author{
XIAOXIONG WANG ${ }^{1,2}$, SHIRONG CHEN ${ }^{1,2}$, TAIPENG SHEN $^{1,2}$, HAO LU $^{1,2}$, \\ DINGQIONG XIAO ${ }^{1,2}$, MENG ZHAO ${ }^{1,2}$, YUTANG YAO ${ }^{1,2}$, XIULI LI $^{1,2}$, GE ZHANG $^{1,2}$, \\ $\mathrm{XING}_{\mathrm{ZHOU}}{ }^{1,2}$, XIAO JIANG ${ }^{1,2}$ and ZHUZHONG CHENG ${ }^{1,2}$ \\ ${ }^{1}$ Positron Emission Tomography/Computed Tomography Center, Sichuan Cancer Hospital and Institute, \\ Sichuan Cancer Center, School of Medicine, University of Electronic Science and Technology of China; \\ ${ }^{2}$ Radiation Oncology Key Laboratory of Sichuan Province, Chengdu, Sichuan 610041, P.R. China
}

Received February 19, 2019; Accepted September 13, 2019

DOI: $10.3892 /$ etm.2020.8422

\begin{abstract}
Breast cancer remains one of the leading causes of mortality in women, and epithelial-mesenchymal transition (EMT) serves an indispensable role in the invasion and migration of breast cancer cells. As a representative of classical histone deacetylase inhibitors (HDACIs), trichostatin A (TSA) has been demonstrated to reverse EMT in certain types of non-tumor cells and tumor cells. In the present study, the invasive and migratory abilities of MCF-7 cells were examined following treatment with TSA. TSA-induced changes in the expression of an epithelial biomarker epithelial cadherin (E-cadherin), a mesenchymal biomarker (vimentin), and a transcription factor [zinc finger protein SNAI2 (SLUG)] were also investigated. Transwell invasion and migration assays, and wound healing assays, revealed that the invasive and migratory abilities of MCF-7 cells were suppressed significantly upon treatment with TSA. Treatment with TSA led to an increased expression level of E-cadherin, and decreased expression of vimentin and, in MCF-7 cells. The overexpression of SLUG decreased the expression level of E-cadherin, but increased vimentin expression, and upon treatment with TSA, these effects were reversed. Additionally, SLUG knockdown also led to upregulation of E-cadherin expression, downregulation of vimentin expression, and suppression of the invasion and migration of MCF-7 cells. Taken together, these results suggest that TSA is able to reverse EMT via suppressing SLUG and attenuate the invasion and migration of MCF-7 cells in vitro,
\end{abstract}

Correspondence to: Dr Xiao Jiang or Dr Zhuzhong Cheng, Positron Emission Tomography/Computed Tomography Center, Sichuan Cancer Hospital and Institute, Sichuan Cancer Center, School of Medicine, University of Electronic Science and Technology of China, 55 Section 4, Renmin South Road, Chengdu, Sichuan 610041, P.R. China

E-mail: jiangxiao401@gmail.com

E-mail: chengzhuzhong@163.com

Key words: breast cancer, epithelial-mesenchymal transition, trichostatin A, histone deacetylase inhibitor, biomarkers thereby providing a potential avenue for chemotherapeutic intervention in the treatment of breast cancer.

\section{Introduction}

Breast cancer is one of the most common malignant diseases in women worldwide and its metastasis to distant organs is the leading cause of mortality in these patients. The metastatic sites from primary breast cancer are usually the brain, liver, lungs and bone tissue $(1,2)$, whereas distant metastases to other organs, including the uterus, kidney or spleen, are relatively rare. When patients are diagnosed with breast cancer, $10-15 \%$ of them develop an aggressive phenotype, and distant metastasis occurs within 3 years. However, it is not unusual that metastases at distant sites may appear $\geq 10$ years following the initial diagnosis (3). Therefore, patients with breast cancer are at risk of developing lethal metastasis throughout their entire lifetime.

Epithelial-mesenchymal transition (EMT) is considered to be closely associated with the invasion and migration of tumor cells, and it is characterized by a cellular phenotypic transformation involving acquisition of mesenchymal characteristics and loss of epithelial characteristics (4-7). The epithelial and mesenchymal phenotypes are distinct cellular states; cells are able to transition between each state (8). Additionally, EMT has been regarded as a reversible process that may be prevented under certain physiological and pathological conditions. Epithelial cadherin (E-cadherin) is an important epithelial cell adhesion molecule, and a decrease in the level of E-cadherin is one of the landmark features of EMT. The other important phenomenon associated with EMT is the upregulation of mesenchymal biomarkers such as vimentin and $\mathrm{N}$-cadherin $(9,10)$. Clinical studies have revealed that breast cancer, when accompanied by a low expression of E-cadherin and robust expression of vimentin or $\mathrm{N}$-cadherin, usually exhibits an aggressive tumor phenotype and a high rate of metastasis $(7,11)$.

Certain transcription factors, such as zinc finger protein SNAI2 (SLUG), zinc finger protein SNAI1 (Snail), twist-related protein 1 (Twist) and zinc finger E-box-binding homeobox 1 (Zeb1), have been implicated in EMT regulation. Among 
them, the transcription factor SLUG inhibits the expression of E-cadherin by binding to the E-box site on the E-cadherin promoter. Upregulation of SLUG results in a decrease in the levels of E-cadherin $(12,13)$, which subsequently leads to an attenuation of intercellular adhesion and enhanced cell motility properties. Furthermore, SLUG is able to promote the expression of vimentin, consequently inducing EMT-like changes (14). Therefore, SLUG has an important role in promoting the EMT process.

Histone deacetylase inhibitors (HDACIs) are a class of anti-tumor drugs that exhibit potent anti-tumor activity $(15,16)$. As a representative of the classical HDACIs, trichostatin A (TSA) suppresses the activity of histone deacetylases (HDACs) in a non-competitive and reversible manner. Previously published studies have revealed that TSA reverses EMT in non-tumor cells, including human renal tubular epithelial cells, retinal pigment epithelium cells and hepatocytes (17-19). Furthermore, a previously published study by our research group identified that EMT was prevented by TSA in SW480 and PC3 cells (20). Given these data, we hypothesized that TSA-induced EMT reversal effects may also occur in breast cancer cells. Therefore, in the present study, TSA-mediated changes in EMT-associated biomarkers, including E-cadherin, vimentin and the transcription factor SLUG, were investigated, and TSA-induced alterations in the invasive and migratory abilities of MCF-7 breast cancer cells were determined.

\section{Materials and methods}

Cell culture and cytotoxicity test. The human breast cancer cell line MCF-7 was obtained from the Cell Bank of Type Culture Collection of Chinese Academy of Sciences. The cells were cultured in RPMI-1640 medium (Invitrogen; Thermo Fisher Scientific, Inc.) under an atmosphere of $37^{\circ} \mathrm{C}$ humidified air containing $5 \% \mathrm{CO}_{2}$ supplemented with $1 \%$ penicillin/streptomycin (Invitrogen; Thermo Fisher Scientific, Inc.) and 10\% fetal bovine serum (HyClone; GE Healthcare Life Sciences). Cytotoxicity of TSA (Sigma-Aldrich; Merck KGaA) on MCF-7 cells was detected using an MTS assay (Promega Corporation), according to the manufacturer's protocol. In brief, MCF-7 cells were plated into 96-well culture plates (5,000 cells in $200 \mu \mathrm{l}$ per well) overnight and subsequently treated with $50,100,200,400$ or $800 \mathrm{nM}$ TSA for 24 or $48 \mathrm{~h}$. Cells were rinsed with PBS to remove unattached cells and incubated with $20 \%$ MTS reagent in serum-free medium for $3 \mathrm{~h}$ at $37^{\circ} \mathrm{C}$. The absorbance of the formazan dye was measured at $490 \mathrm{~nm}$ using a microplate reader (Bio-Rad Laboratories, Inc.), and the optical density (OD) at $490 \mathrm{~nm}$ (OD490) was directly proportional to the proportion of viable cells. Cell viability (\% of control $)=($ OD490 of treatment group-OD490 of blank group)/(OD490 of control group-OD490 of blank group) $\mathrm{x} 100 \%$.

Transwell invasion and migration assay. Invasion and migration assays were performed as follows: Boyden chambers equipped with $8-\mu \mathrm{m}$ polycarbonate filters were coated with Matrigel $^{\mathrm{TM}}$ matrix (BD Biosciences) at $37^{\circ} \mathrm{C}$ and dried overnight under sterile conditions for the invasion assay, whereas Matrige ${ }^{\mathrm{TM}}$ matrix-free polycarbonate filters were used for the migration assay. Subsequently, MCF-7 cells suspended in
$300 \mu 1$ RPMI-1640 medium containing 1\% FBS were seeded in the upper chamber at a density of $1 \times 10^{5} /$ well, whereas $600 \mu$ R RMI-1640 medium with 10\% FBS (chemotactic agent) was added to the lower chamber. Cells were incubated with or without $100 \mathrm{nM}$ TSA at $37^{\circ} \mathrm{C}$ for $48 \mathrm{~h}$. For the invasion assay, following gentle removal of the Matrigel that had been coated on the upper side of the filter, cells adhering to the underside of the filter were fixed with $4 \%$ paraformaldehyde at room temperature for $20 \mathrm{~min}$, and subsequently stained with DAPI $(10 \mathrm{ug} / \mathrm{ml})$ at room temperature for $10 \mathrm{~min}$. For the migration assay, cells that had passed through the pores of the filter and fallen into the lower chamber were fixed with $4 \%$ paraformaldehyde at room temperature for $20 \mathrm{~min}$, and subsequently stained with $0.5 \%$ hematoxylin at room temperature for $15 \mathrm{~min}$. An upright fluorescent microscope (Nikon Corporation) was used for counting cells (5 fields/chamber) at a magnification of x100. Each invasion and migration experiment was repeated at least 3 times.

Wound healing assay. MCF-7 cells $\left(4 \times 10^{5}\right)$ were seeded in each well of 6-well plates and were cultured in RPMI-1640 medium containing $10 \%$ FBS until growth was confluent. A defined scratch was made with a 200- $\mu$ l pipette tip (cat. no. 94052320; Thermo Fisher Scientific, Inc.), generating a cell-free area of $\sim 0.5 \mathrm{~mm}$ in width. Cellular debris was gently removed by washing with culture medium. Subsequently, cells were cultured in serum-free RPMI-1640 with or without $100 \mathrm{nM}$ TSA for 24 or $48 \mathrm{~h}$. Images of the scraped area were captured using an inverted microscope (Olympus Corporation) at magnification, $x 100$. The percentages of wound closure were subsequently calculated by the following equation: Wound closure $\%=\left[1-\left(\right.\right.$ wound area at $T_{\mathrm{t}} /$ wound area at $\left.\left.T_{0}\right)\right]$, where $T_{\mathrm{t}}$ is the time after wounding and $T_{0}$ is the time immediately following wounding. A total of 3 independent experiments were performed.

Reverse transcription-quantitative polymerase chain reaction (RT-qPCR). Briefly, after $48 \mathrm{~h}$ incubation with or without $100 \mathrm{nM}$ TSA, MCF-7 cells were washed twice with ice-clod PBS, and total mRNA was extracted using TRIzol ${ }^{\circledR}$ reagent (Invitrogen; Thermo Fisher Scientific, Inc.). First-strand cDNA was generated by reverse transcription from $500 \mathrm{ng}$ total RNA using a PrimeScript ${ }^{\mathrm{TM}}$ RT reagent Kit (Takara Bio, Inc.) and the cDNA was synthesized at $37^{\circ} \mathrm{C}$ for $15 \mathrm{~min}$. The relative gene expression of target and reference genes was assessed using a LightCycler ${ }^{\circledR} 480$ system (Roche Applied Science) using validated primers for E-cadherin, vimentin, SLUG, GAPDH and SYBR Premix Ex Taq ${ }^{\mathrm{TM}}$ (Takara Bio, Inc.) for detection. The thermocycling conditions were as follows: $10 \mathrm{~min}$ at $95^{\circ} \mathrm{C}$, followed by 40 cycles of denaturation at $95^{\circ} \mathrm{C}$ for $15 \mathrm{sec}$, annealing at $60^{\circ} \mathrm{C}$ for $30 \mathrm{sec}$ and extension at $72^{\circ} \mathrm{C}$ for $30 \mathrm{sec}$. The ratio between the target gene and GAPDH was used to calculate the relative quantitation. The relative expression of the amplification products was analyzed using the $2^{-\Delta \Delta \mathrm{Cq}}$ method (21). Data are presented as the mean \pm standard deviation from 3 independent experiments. Primer sequences used in the RT-qPCR were as follows: E-cadherin forward, 5'-TACACTGCCCAGGAGCCAGA-3'; E-cadherin reverse, 5'-TGGCACCAGTGTCCGGATTA-3'; vimentin forward, 5'-TGAGTACCGGAGACAGGTGCAG-3'; vimentin reverse, 

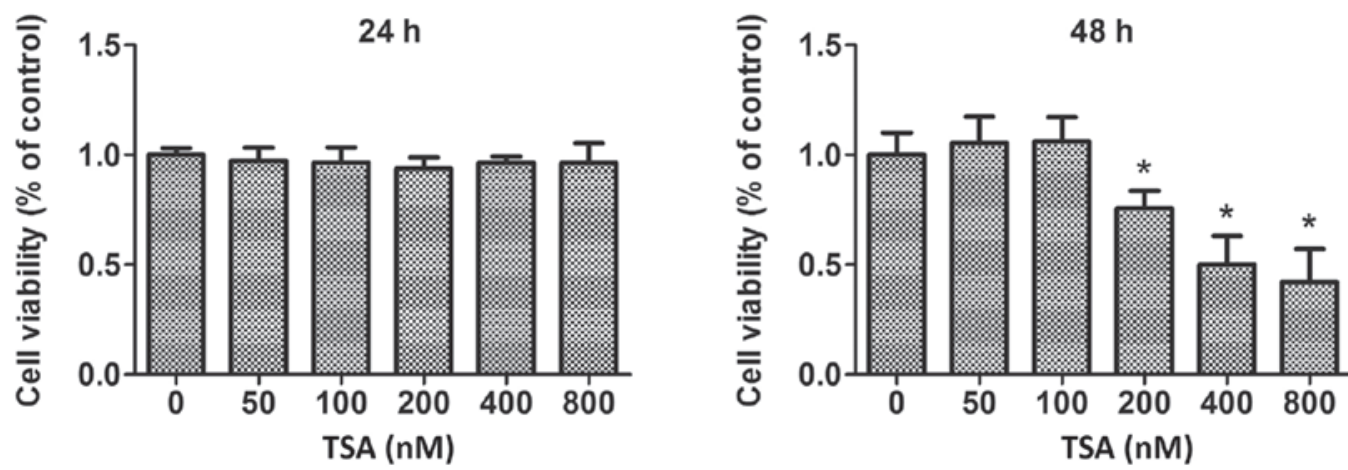

Figure 1. Effect of different concentrations of TSA on cell proliferation. MCF-7 cells were treated with various concentrations of TSA, and cell viability was determined using the MTS assay. ${ }^{*}<<0.05$ vs. control. TSA, trichostatin A.

5'-TAGCAGCTTCAACGGCAAAGTTC-3'; SLUG forward, 5'-TTCGGACCCACACATTACCT-3'; SLUG reverse, 5'-GCA GTGAGGGCAAGAAAAAG-3'; GAPDH forward, 5'-GCA CCGTCAAGGCTGAGAAC-3'; and GAPDH reverse, 5'-TGG TGAAGACGCCAGTGGA-3'.

Western blot analysis. Briefly, MCF-7 cells were incubated at $37^{\circ} \mathrm{C}$ for $48 \mathrm{~h}$ and treated with or without $100 \mathrm{nM}$ TSA. Subsequently, cells were washed 3 times with ice-cold PBS and lysed on ice in cell lysis buffer and the cell debris was removed by centrifugation at $12,000 \mathrm{x} \mathrm{g}$ at $4^{\circ} \mathrm{C}$ for $2 \mathrm{~min}$. Total protein was quantified using a bicinchoninic acid assay kit (cat. no. P0010; Beyotime Institute of Biotechnology) and samples containing equal amounts of protein $(60 \mu \mathrm{g} / \mathrm{lane})$ were separated by $10 \%$ SDS-PAGE, and subsequently transferred onto PVDF membranes. The membranes were blocked with 5\% non-fat milk for $2 \mathrm{~h}$ at room temperature, and subsequently incubated with the primary antibodies against $\beta$-actin $(1: 1,000$; cat. no., sc-8432; Santa Cruz Biotechnology, Inc.), E-cadherin (1:1,000; cat. no., sc-71008; Santa Cruz Biotechnology, Inc.), vimentin (1:1,000; cat. no., sc-80975; Santa Cruz Biotechnology, Inc.), SLUG (1:1,000; cat. no., sc-166476; Santa Cruz Biotechnology, Inc.) overnight at $4^{\circ} \mathrm{C}$. Following incubation with the appropriate horseradish peroxidase-conjugated secondary antibodies (1:5,000; cat. no., sc-2031; Santa Cruz Biotechnology, Inc.) for $2 \mathrm{~h}$ at room temperature, specific immune complexes were detected with chemiluminescence reagent (Western Lightning ${ }^{\mathrm{TM}}$, Chemiluminescence Reagent Plus, PerkinElmer, Inc.). The detection of $\beta$-actin was used as a loading control (22). Protein expression was quantified using ImageJ software (version 1.46, National Institutes of Health).

Confocal microscopy for E-cadherin. MCF-7 cells $\left(3 \times 10^{5}\right)$ were seeded in a $35-\mathrm{mm}$ glass bottom dish. When grown to $\sim 70 \%$ confluence, cells were stimulated with or without $100 \mathrm{nM}$ TSA for $48 \mathrm{~h}$. Following fixation in $4 \%$ paraformaldehyde at $37^{\circ} \mathrm{C}$ for $30 \mathrm{~min}$ the cells were blocked with $10 \%$ normal goat serum (cat. no. 31873, Thermo Fisher Scientific, Inc.) at $37^{\circ} \mathrm{C}$ for $30 \mathrm{~min}$. Cells were then incubated with an antibody against E-cadherin (1:100; cat. no., sc-71008; Santa Cruz Biotechnology, Inc.) for $1 \mathrm{~h}$ at $37^{\circ} \mathrm{C}$. Subsequently, slides were washed three times with PBS and incubated with Alexa Fluor 488-conjugated secondary antibodies (1:1,000; Invitrogen; Thermo Fisher Scientific, Inc.) for $45 \mathrm{~min}$ at $37^{\circ} \mathrm{C}$. Following an additional wash step with PBS, cells were stained with $10 \mu \mathrm{g} / \mathrm{ml}$ DAPI (Invitrogen; Thermo Fisher Scientific, Inc.) at room temperature for $10 \mathrm{~min}$ for the visualization of cell nuclei. The expression of E-cadherin on cell membranes was detected using confocal laser scanning microscopy (LSM710; Zeiss $\mathrm{GmbH}$ ) at magnification, $\mathrm{x} 400$.

Overexpression of SLUG. MCF-7 cells were seeded into a 6 -well plate $\left(2 \times 10^{5}\right.$ cells/well $)$ and cultured at $37^{\circ} \mathrm{C}$ until the following day. In serum-free medium, cells were transfected with $2 \mu \mathrm{g}$ control vector pcDNA-3.1 (Generay Biotech Co., Ltd) or $2 \mu \mathrm{g}$ pcDNA-SLUG, encoding the human SLUG gene (Generay Biotech Co., Ltd) mixed with Lipofectamine ${ }^{\mathrm{TM}}$ 2000 reagent (Invitrogen; Thermo Fisher Scientific, Inc.). The serum-free medium was then replaced with complete culture medium $6 \mathrm{~h}$ later and the transfection efficiency was evaluated by RT-qPCR and western blot analysis, as aforementioned.

SLUG small interfering RNA (siRNA) transfections. MCF-7 cells were seeded in 6-well plates at a density of $3 \times 10^{5}$ cells/well and grown for $24 \mathrm{~h}$. Cell transfections were performed using Lipofectamine $^{\mathrm{TM}}$ RNAi MAX reagent (Invitrogen; Thermo Fisher Scientific, Inc.) according to the manufacturer's protocol. A validated negative control oligonucleotide (5'-GCAACG UACAGUGGUUCAA-3'/5'-UUGAACCACUGUACGUUGC-3', Guangzhou RiboBio Co., Ltd.) and the siRNA oligonucleotides targeting SLUG (5'-GCAUUUGCAGACAGGUCAA-3'/5'-UUG AACUGUCUGCAAAUGC-3', Guangzhou RiboBio Co., Ltd, Guangzhou, China) were used for transfection. The final siRNA oligonucleotide concentration was $20 \mathrm{pM}$ and the transfection efficiency was evaluated by western blot analysis. Following $48 \mathrm{~h}$ transfection, cells were collected for subsequent assays.

Statistical analysis. All statistical analyses were performed using GraphPad Prism v.5.0 software (GraphPad Software Inc.). A Student's t-test was used to analyze differences between two groups. One-way analysis of variance followed by Tukey's post-hoc test was used to analyze differences among multiple groups. Data are presented as the mean \pm standard deviation from at least 3 independent experiments. $\mathrm{P}<0.05$ was considered to indicate a statistically significant difference. 
A

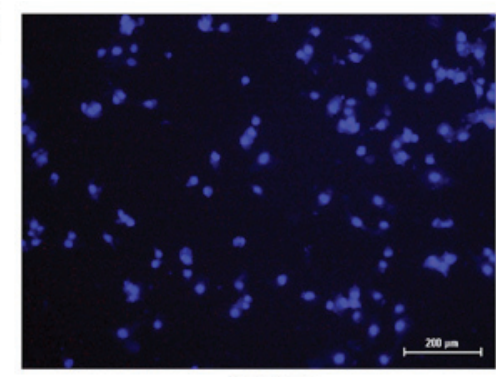

Control

B

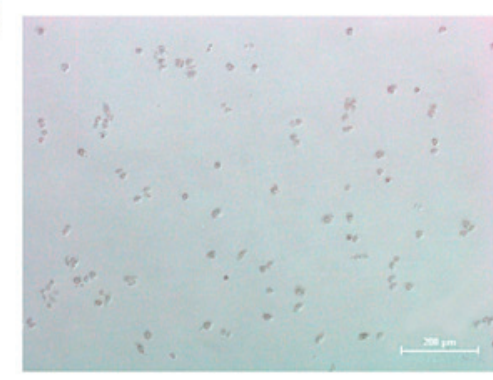

Control

C

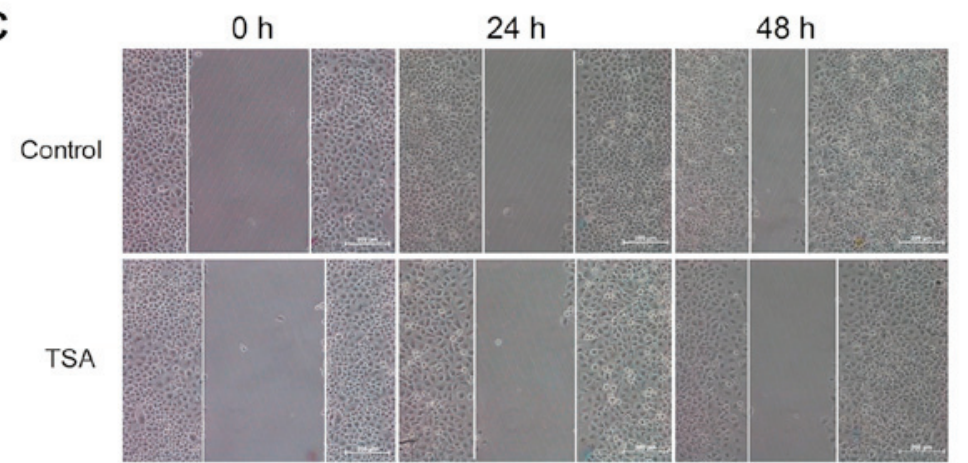

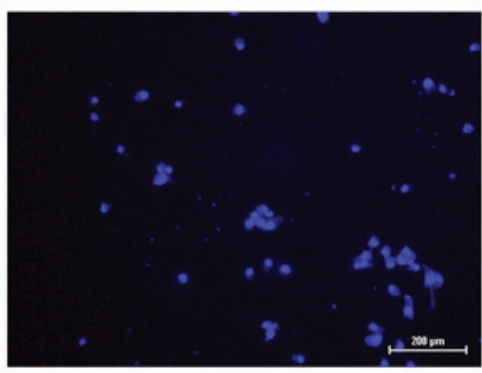

TSA

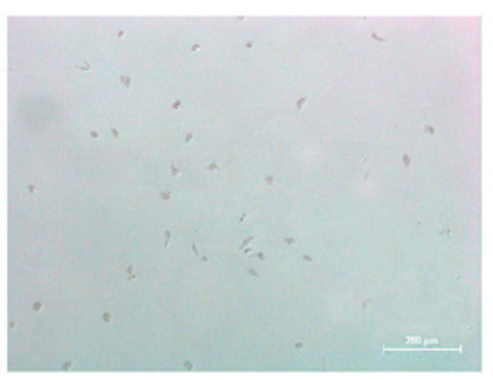

TSA

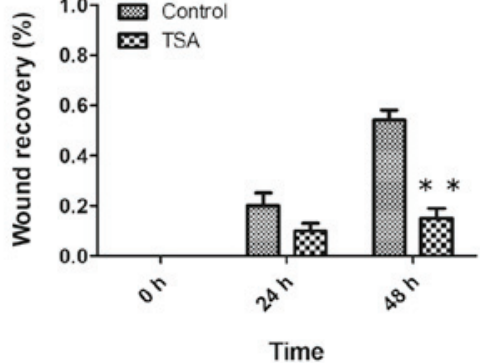

Figure 2. TSA attenuates the invasion and migration of MCF-7 cells. (A) MCF-7 cells were incubated with or without TSA, and images were captured of the invasive cells. Scale bar, $200 \mu \mathrm{m} .{ }^{* *} \mathrm{P}<0.01$ vs. control. (B) MCF-7 cells were treated with or without TSA, and images were captured of the migrated cells. Scale bar $=200 \mu \mathrm{m}$. ${ }^{* *} \mathrm{P}<0.01$ vs. control. (C) MCF-7 cells were treated with or without TSA, and the scratch wound size was monitored. Scale bar, $200 \mu \mathrm{m}$. ${ }^{* *} \mathrm{P}<0.01$ vs. control. TSA, trichostatin A.

\section{Results}

TSA attenuates invasion and migration of MCF-7 cells. Transwell invasion and migration assays were performed to investigate the invasive and migratory abilities of MCF-7 cells. Furthermore, TSA-mediated anti-proliferative effects were also determined by MTS assay. These experiments revealed that treatment with $100 \mathrm{nM}$ TSA elicited no significant inhibitory activity on the proliferation of MCF-7 cells within a $48 \mathrm{~h}$ period (Fig. 1). However, following treatment with $100 \mathrm{nM}$ TSA for $48 \mathrm{~h}$, the numbers of invasive cells adhering to the underside of the filter (Fig. 2A) and migrated cells in the lower chamber (Fig. 2B) had decreased markedly compared with the control. Additionally, the results of the wound healing assay revealed that treatment with TSA caused a decrease in the migratory capacity of the MCF-7 cells (Fig. 2C). These results suggested that the decreased invasive and migration capabilities of the cells following TSA treatment may have resulted from reversion of EMT, rather than having been caused by any anti-proliferation effect. Taken together, we concluded that the invasive and migratory abilities of MCF-7 cells were attenuated by TSA.
TSA reverses EMT in MCF-7 cells. As aforementioned, the epithelial and mesenchymal phenotypes are distinct cellular states, and cells are capable of transitioning between them. The expression levels of EMT-associated biomarkers and transcription factors reflect the nature of the cell phenotype. Therefore, in MCF-7 cells, changes in TSA-induced mRNA and protein expression levels of E-cadherin, vimentin and SLUG were determined. RT-qPCR analysis revealed that TSA led to an upregulation of E-cadherin, and a downregulation of vimentin and SLUG mRNA expression levels (Fig. 3A). Similarly, at the protein level, an increased expression of E-cadherin, and a decrease in the expression levels of vimentin and SLUG were determined via western blot analysis (Fig. 3B; Table I.). Furthermore, following treatment with TSA, changes in the expression level of E-cadherin on the cell membrane were also detected by confocal microscopy. TSA-induced increases of E-cadherin was observed visually (Fig. 3C). Taken together, these results suggested that TSA was able to reverse EMT in MCF-7 cells.

TSA-induced suppression of SLUG is involved in reversing EMT. SLUG exerts a crucial role in promoting the EMT process. 

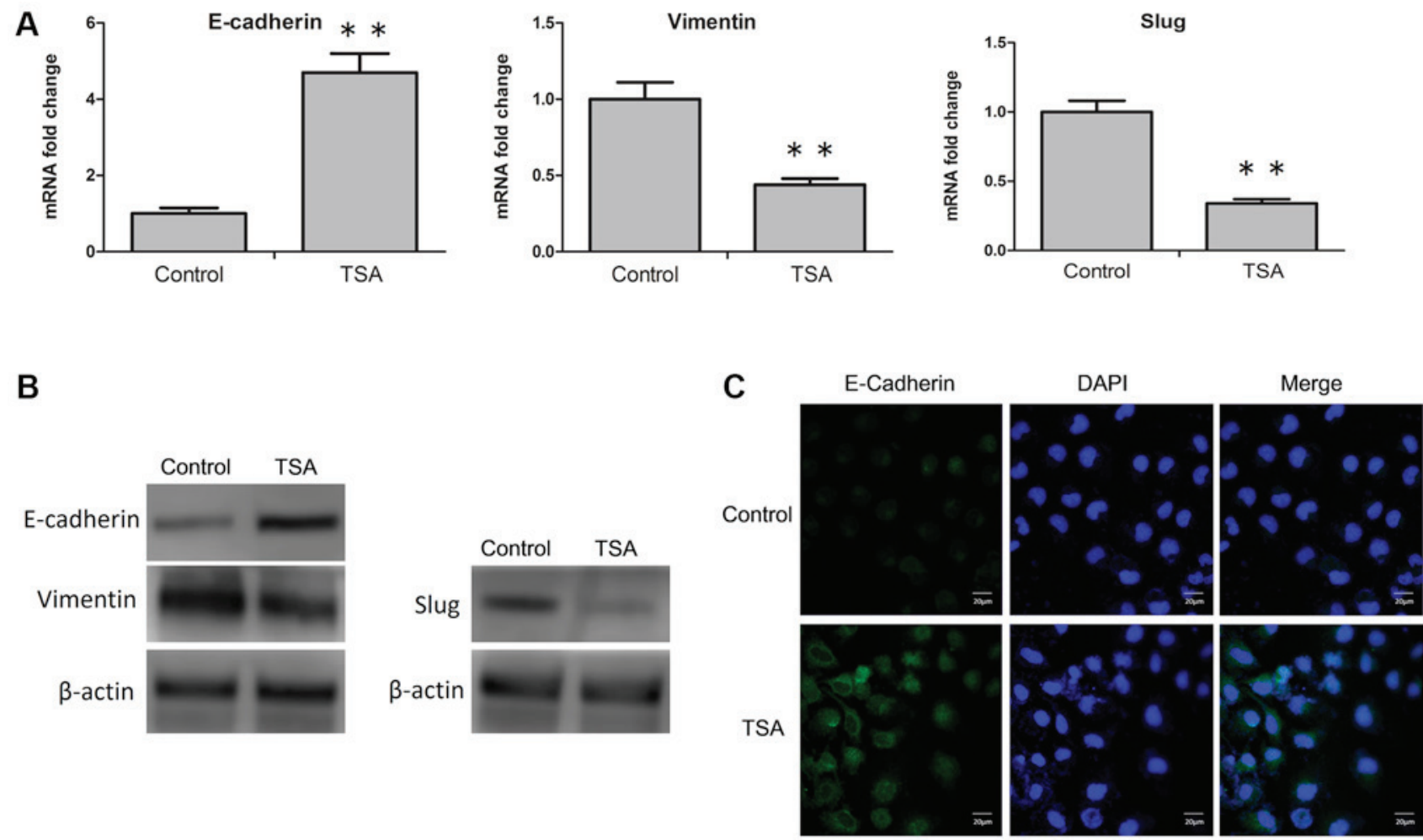

Figure 3. Treatment with TSA reverses EMT in MCF-7 cells. (A) MCF-7 cells were treated with or without TSA, and the mRNA level of E-cadherin, vimentin and SLUG were analyzed by reverse transcription-quantitative polymerase chain reaction. ${ }^{* *} \mathrm{P}<0.01$ vs. control. (B) MCF-7 cells were incubated with or without TSA, and subsequently the protein levels of E-cadherin, vimentin and SLUG were analyzed by western blot analysis. (C) MCF-7 cells were treated with or without TSA, and the cellular location of E-cadherin (green) was examined by confocal microscopy. Scale bar, $20 \mu \mathrm{m}$. TSA, trichostatin A; EMT, epithelial-mesenchymal transition; E-cadherin, epithelial cadherin; SLUG, zinc finger protein SNAI2.

Table I. Protein levels of E-Cadherin, vimentin and SLUG in MCF7 cells incubated with or without TSA.

\begin{tabular}{lcl}
\hline Group & Control & \multicolumn{1}{c}{ TSA } \\
\hline E-cadherin/ $\beta$-actin expression & $0.70 \pm 0.041$ & $1.38 \pm 0.0097^{\mathrm{a}}$ \\
Vimentin/ $\beta$-actin expression & $0.99 \pm 0.038$ & $0.51 \pm 0.028^{\mathrm{a}}$ \\
SLUG/ $\beta$-actin expression & $1.02 \pm 0.037$ & $0.35 \pm 0.0095^{\mathrm{a}}$ \\
\hline
\end{tabular}

${ }^{\mathrm{a}} \mathrm{P}<0.001$ vs. control group. Data are expressed as the mean $\pm \mathrm{SD}$. E-cadherin, epithelial cadherin; SLUG, zinc finger protein SNAI2; TSA, trichostatin A.

In MCF-7 cells, upregulation of E-cadherin and downregulation of vimentin may be due to TSA-mediated suppression of SLUG. To investigate this, the control vector pcDNA-3.1 and pcDNA-SLUG were transfected into MCF-7 cells, and changes in the mRNA and protein levels of SLUG, E-cadherin and vimentin were examined. The results revealed that E-cadherin was downregulated, and SLUG and vimentin were upregulated, at the mRNA (Fig. 4A) and protein (Fig. 4B; Table II) levels. Furthermore, following treatment with $100 \mathrm{nM}$ TSA for $48 \mathrm{~h}$, these changes were reversed in the SLUG-overexpressing cells (Fig. 4A and B; Table II). Additionally, the expression levels of SLUG, E-cadherin and vimentin protein were detected in SLUG siRNA-transfected MCF-7 cells compared with control siRNA-transfected MCF-7 cells. The invasive and migratory
Table II. Protein levels of SLUG, E-Cadherin and vimentin in cells transfected with pcDNA-3.1 or pcDNA-SLUG and incubated with or without TSA.

\begin{tabular}{lccc}
\hline & pcDNA-3.1 & $\begin{array}{c}\text { pcDNA- } \\
\text { SLUG }\end{array}$ & $\begin{array}{c}\text { pcDNA- } \\
\text { SLUG + TSA }\end{array}$ \\
\hline $\begin{array}{l}\text { SLUG/ } \beta \text {-actin } \\
\text { expression }\end{array}$ & $1.54 \pm 0.068$ & $3.06 \pm 0.34^{\mathrm{b}}$ & $1.13 \pm 0.076^{\mathrm{aa}}$ \\
$\begin{array}{l}\text { E-cadherin/ } \beta \text {-actin } \\
\text { expression }\end{array}$ & $2.08 \pm 0.081$ & $1.37 \pm 0.13^{\mathrm{b}}$ & $1.83 \pm 0.07^{\mathrm{bb}}$ \\
$\begin{array}{l}\text { Vimentin/ } \beta \text {-actin } \\
\text { expression }\end{array}$ & $0.29 \pm 0.019$ & $1.20 \pm 0.11^{\mathrm{a}}$ & $0.75 \pm 0.059^{\mathrm{bb}}$ \\
\hline
\end{tabular}

Data are expressed as the mean $\pm \mathrm{SD}$. ${ }^{\mathrm{a}} \mathrm{P}<0.001$ vs.pcDNA-3.1 group; ${ }^{\mathrm{b}} \mathrm{P}<0.01$ vs. pcDNA-3.1 group; ${ }^{\mathrm{a}} \mathrm{P}<0.001$ vs. pcDNA-SLUG group; ${ }^{\text {bb }} \mathrm{P}<0.01$ vs. pcDNA-SLUG group. E-cadherin, epithelial cadherin; SLUG, zinc finger protein SNAI2; TSA, trichostatin A.

abilities of the two groups were also investigated by Transwell invasion and migration assays. As indicated in Fig. 4C and D, SLUG knockdown led to an upregulation of E-cadherin, and a downregulation of vimentin, at the protein level (Fig. 4D; Table III). Compared with the siNC group, cells transfected with SLUG siRNA exhibited decreased levels of invasion and migration (Fig. 4C). These results indicated that TSA-mediated suppression of SLUG was involved in the reversal of EMT. 

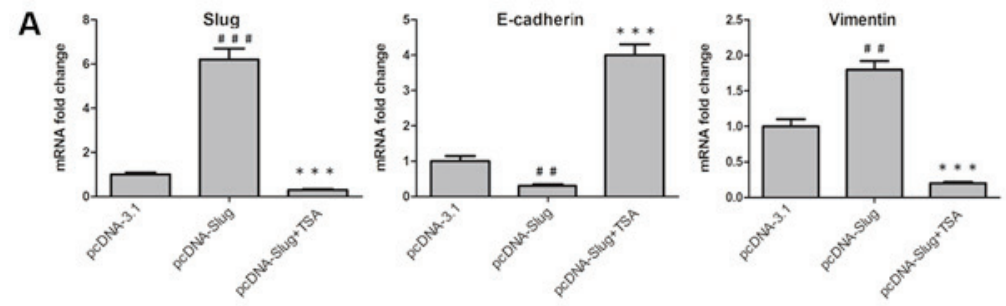

C
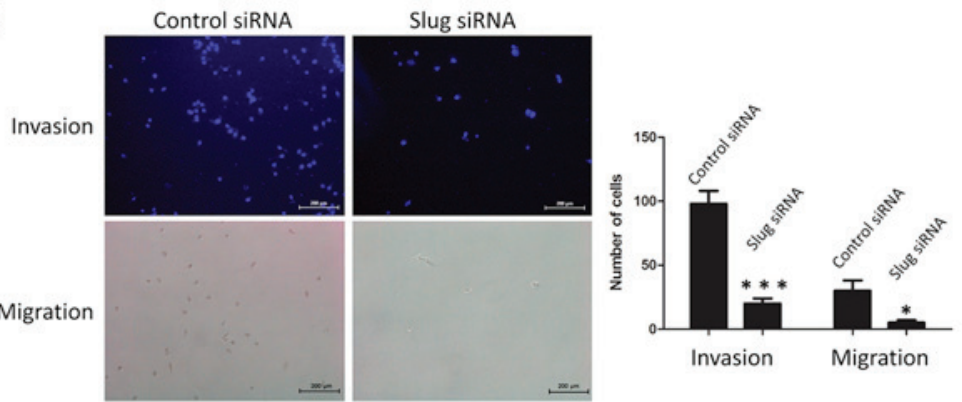
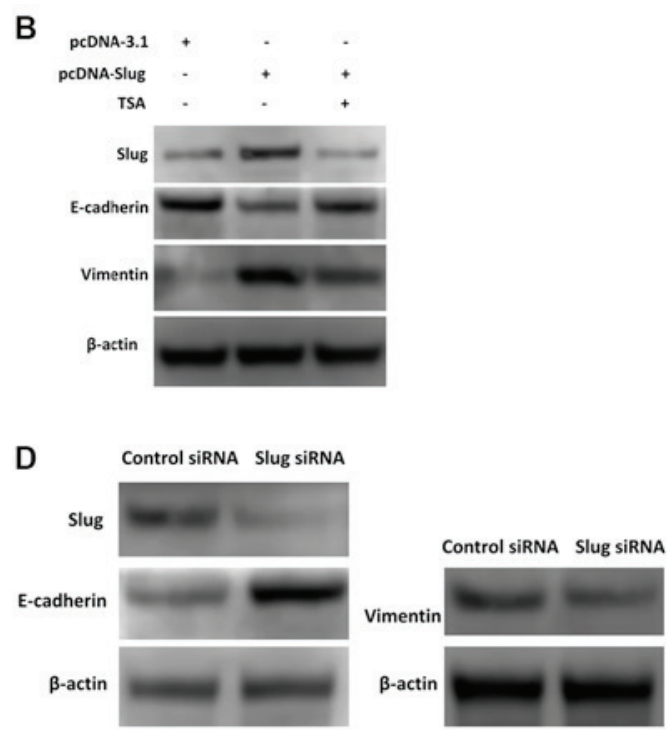

Figure 4. TSA-mediated suppression of SLUG is involved in reversing EMT. (A) pcDNA-3.1 and pcDNA-SLUG were expressed in MCF-7 cells, and cells with pcDNA-SLUG were treated with or without TSA. Subsequently, the mRNA levels of SLUG, E-cadherin and vimentin were examined by reverse transcription-quantitative polymerase chain reaction. ${ }^{\# \#} \mathrm{P}<0.01$ and ${ }^{\# \# \#} \mathrm{P}<0.001$ vs. pcDNA-3.1. ${ }^{* *} \mathrm{P}<0.01$ and ${ }^{* * *} \mathrm{P}<0.001$ vs. pcDNA-SLUG. (B) pcDNA-3.1 and pcDNA-SLUG were expressed in MCF-7 cells, and cells with pcDNA-SLUG were incubated with or without TSA. Subsequently, the protein levels of SLUG, E-cadherin and vimentin were examined by western blot analysis. (C) SLUG siRNA or control siRNA was transfected in MCF-7 cells, and images were captured of the invasive and migrated cells. Scale bar $=200 \mu \mathrm{m}$. ${ }^{*} \mathrm{P}<0.05$ and ${ }^{* * *} \mathrm{P}<0.001$ vs. control. (D) SLUG siRNA or control siRNA were transfected in MCF-7 cells, and subsequently the expression levels of SLUG, E-cadherin, and vimentin protein were examined by western blot analysis. TSA, trichostatin A; EMT, epithelial-mesenchymal transition; SLUG, zinc finger protein SNAI2; E-cadherin, epithelial cadherin; siRNA, small interfering RNA.

Table III. Protein levels of SLUG, E-Cadherin and vimentin in cells transfected with control siRNA or SLUG siRNA.

Control siRNA SLUG siRNA

\begin{tabular}{lrc}
\hline SLUG/ $\beta$-actin expression & $1.019 \pm 0.037$ & $0.28 \pm 0.0071^{\mathrm{a}}$ \\
E-cadherin/ $\beta$-actin expression & $1.19 \pm 0.011$ & $2.28 \pm 0.034^{\mathrm{a}}$ \\
Vimentin/ $\beta$-actin expression & $0.59 \pm 0.063$ & $0.32 \pm 0.083^{\mathrm{b}}$ \\
\hline
\end{tabular}

Data are expressed as the mean $\pm \mathrm{SD}$. ${ }^{\mathrm{a}} \mathrm{P}<0.001 \mathrm{vs}$. control siRNA group; ${ }^{\mathrm{b}} \mathrm{P}<0.05$ vs. control siRNA group. E-cadherin, epithelial cadherin; si, short interfering; SLUG, zinc finger protein SNAI2; TSA, trichostatin A.

\section{Discussion}

It has been well established that E-cadherin and vimentin are selectively expressed, and perform their specific functions in epithelial and mesenchymal cellular states, respectively. E-cadherin is a membrane glycoprotein that normally binds to another connexin, $\beta$-catenin, to maintain the integrity of the morphology and skeletal structure of epithelial cells. When the expression of E-cadherin is decreased, the levels of connectivity between tumor cells decrease, and the dispersed tumor cells become more motile, which consequently facilitates the processes of tumor invasion and migration. Vimentin is a structural cytoskeletal protein that constitutes the intermediate filaments of mesenchymal cells. High expression of E-cadherin, and the absence of vimentin, is associated with a low likelihood that cancer cells will be able to invade and migrate $(23,24)$. In the present study, TSA-mediated increases in E-cadherin and decreases in vimentin were observed, and TSA-induced suppression of the invasion and migration capabilities of the MCF-7 cells was also confirmed, which were phenomena that suppressed the distant migration of MCF-7 cells.

In addition, the transcription factor SLUG was downregulated following treatment with TSA. Typically, EMT-inducing transcription factors are classified into two groups: For example, SLUG, SNAIL, Krueppel-like factor 8, transcription factor 3 and Zeb1 repress E-cadherin transcription in a direct manner, whereas transcription factors such as Twist, Forkhead box protein C2, transcription factor 4 and Goosecoid repress activity of the E-cadherin promoter indirectly (25). Importantly, these transcription factors are involved in the downregulation of E-cadherin. Furthermore, SLUG is also able to promote the expression of vimentin, and consequently induce EMT-like changes (14). The results of the present study indicated that SLUG was able to induce downregulation of E-cadherin, and upregulation of vimentin in MCF-7 cells, and TSA-mediated suppression of SLUG was involved in the process of reversing EMT. In addition, a large number of previously published studies have suggested that SLUG promotes the initial stages of EMT in lung, bladder, colorectal, prostate and nasopharyngeal cancer cells (26-31). Therefore, TSA-mediated repression of SLUG may be the critical factor with respect to the observed effect of EMT reversal.

HDACs are involved in various physiological and pathological regulatory processes, and HDACIs exert potent EMT-reversal effects on several types of non-tumor cells, and on tumor cells. TSA-mediated reversal of EMT is closely associated with the transforming growth factor- $\beta$ (TGF- $\beta$ ) signaling pathway. It has reported that HDAC1 and HDAC2 are involved in TGF- $\beta$-induced EMT, and TSA completely inhibits TGF- $\beta$-mediated EMT in hepatocytes and kidney tubular 
epithelial cells $(32,33)$. In retinal pigment epithelium cells $(34)$, TSA-mediated inhibition of HDAC activity was demonstrated to markedly suppress cellular proliferation and TGF- $\beta$-induced EMT. In addition, TSA inhibited TGF- $\beta 2$-mediated EMT via regulating not only the canonical Smad signaling pathway, but also the non-canonical TGF- $\beta / \mathrm{Akt}$, mitogen-activated protein kinase and extracellular signal-regulated kinase 1 and 2 pathways. These studies (32-34) may partly contribute towards our understanding of the mechanism of TSA-mediated inhibition of SLUG expression in the present study. Conversely, our previous study (20) identified that the amounts of HDAC1 and HDAC2 proteins binding to the SLUG gene promoter were increased in the TSA-treated SW480 and PC3 cells. Although few studies have been published on the ability of HDAC inhibitors to induce an increase in the levels of HDACs binding to the target gene promoter, a similar mechanism may be responsible for TSA-induced suppression of SLUG in MCF-7 cells. However, the underlying mechanism requires further investigation.

An increasing number of studies have indicated that EMT not only enhances the invasive and migratory abilities of tumor cells, but also closely contributes to other of their malignant characteristics. It was suggested that human mammary epithelial cells obtained partial stem cell characteristics by inducing EMT transformation, and the epithelial tumor cells with stem cell characteristics were identified to express mesenchymal biomarkers (35). EMT also triggers tumor immunosuppressive properties, assisting in their immune evasion $(36,37)$. For example, certain immunosuppressive cytokines were induced by the EMT-associated transcription factor Snail, leading to differentiation of regulatory $\mathrm{T}$ cells, function damage in dendritic cells, and tumor resistance to cytotoxic $\mathrm{T}$ cells (36). Furthermore, the resistance of tumor cells to chemotherapy, radiotherapy and immunotherapy were also increased by EMT (38-40). In the presence of EMT, breast and cervical cancer cells were demonstrated to be highly resistant to paclitaxel (41-43). The EMT-associated transcription factor SLUG was revealed to be involved in tumor resistance to radiotherapy and chemotherapy by antagonizing p53-mediated apoptosis (44). Finally, SLUG inhibition led to an increase in the radiosensitivity of nasopharyngeal carcinoma (45). Based on these previous studies, it may be possible to conclude from the results of the present study that TSA-induced EMT reversal may have prevented MCF-7 cells from developing into a more malignant phenotype.

In conclusion, the most significant results of the present study were that treatment with TSA reversed EMT and attenuated the invasive and migratory abilities in MCF-7 breast cancer cells. Subsequent studies will involve the detection of the invasive and migratory abilities on the condition of E-cadherin overexpression in the absence of TSA, or blocking of E-cadherin using neutralizing antibody. The EMT-reversal effect of TSA in triple-negative breast cancer cells, including MDA-MB-231 and MDA-MB-435 cells, will also be investigated. Furthermore, ${ }^{18} \mathrm{~F}$-FDG and ${ }^{18} \mathrm{~F}$-FLT positron emission tomography/computed tomography imaging will be employed to evaluate TSA-mediated anti-tumor effects in different types of breast cancer cell lines. However, although these results require further investigation in vivo, the data from the present study have provided novel information regarding the chemotherapy of breast cancer.

\section{Acknowledgements}

Not applicable.

\section{Funding}

The present study was partially supported by Science and Technology Department of Sichuan Province (project 2019YJ0574), Science and Technology Department of Sichuan Province (key project 2017JY0081), and Cadres Health Care of Sichuan Provincial (project no. 2017-803).

\section{Availability of data and materials}

The datasets used and/or analyzed during the present study are available from the corresponding author on reasonable request.

\section{Authors' contributions}

$\mathrm{XW}, \mathrm{XJ}$ and ZC proposed the hypothesis and designed the majority of the experiments. XW wrote the manuscript. XW, SC and TS performed the experiments and analyzed the results. HL, DX, MZ, YY, XL, GZ and XZ assisted in the execution of some experiments. $\mathrm{XJ}$ and $\mathrm{ZC}$ were involved in revising the manuscript. All authors read and approved the final manuscript.

\section{Ethics approval and consent to participate}

Not applicable.

\section{Patient consent for publication}

Not applicable.

\section{Competing interests}

The authors declare that they have no competing interests.

\section{References}

1. Lee YT: Breast carcinoma: Pattern of metastasis at autopsy. J Surg Oncol 23: 175-180, 2010.

2. Weil RJ, Palmieri DC, Bronder JL, Stark AM and Steeg PS: Breast cancer metastasis to the central nervous system. Am J Pathol 167: 913-920, 2005.

3. Vaidya JS, Keshtgar M and Baum M: Diseases of the breast. Br J Cancer 83: 1769-1770, 2000.

4. Behrens J, Mareel MM, Van Roy FM and Birchmeier W: Dissecting tumor cell invasion: Epithelial cells acquire invasive properties after the loss of uvomorulin-mediated cell-cell adhesion. J Cell Biol 108: 2435-2447, 1989.

5. Chengsen X, David P, Christo V, Carol X and Neilson EG: The gatekeeper effect of epithelial-mesenchymal transition regulates the frequency of breast cancer metastasis. Cancer Res 63: 3386-3394, 2003.

6. Thompson EW, Newgreen DF and David T: Carcinoma invasion and metastasis: A role for epithelial-mesenchymal transition? Cancer Res 65: 5991-5995, 2005.

7. Felipe Lima J, Nofech-Mozes S, Bayani J and Bartlett JM: EMT in breast carcinoma-a review. J Clin Med 5: pii: E65, 2016.

8. Jean Paul T and Sleeman JP: Complex networks orchestrate epithelial-mesenchymal transitions. Nat Rev Mol Cell Biol 7: 131-142, 2006.

9. Michael Z and Neilson EG: Biomarkers for epithelial-mesenchymal transitions. J Clin Invest 119: 1429-1437, 2009. 
10. Liu F, Gu LN, Shan BE, Geng CZ and Sang MX: Biomarkers for EMT and MET in breast cancer: An update. Oncol Lett 12: 4869-4876, 2016.

11. David S, Socorro María RP, Hardisson D, Cano A, Moreno-Bueno G and Palacios J: Epithelial-mesenchymal transition in breast cancer relates to the basal-like phenotype. Cancer Res 68: 989-997, 2008.

12. Yi P, Jing L, Zhang Y, Wang N, Liang H, Liu Y, Zhang CY, Zen $\mathrm{K}$ and $\mathrm{Gu} \mathrm{H}$ : SLUG-upregulated miR-221 promotes breast cancer progression through suppressing E-cadherin expression. Sci Rep 6: 25798, 2016.

13. Hajra KM, Chen DY and Fearon ER: The SLUG zinc-finger protein represses E-cadherin in breast cancer. Cancer Res 62: $1613-1618,2002$

14. Vuoriluoto K, Haugen H, Kiviluoto S, Mpindi JP, Nevo J, Gjerdrum C, Tiron C, Lorens JB and Ivaska J: Vimentin regulates EMT induction by SLUG and oncogenic H-Ras and migration by governing Axl expression in breast cancer. Oncogene 30 : $1436-1448,2011$

15. Xu S, Ren J, Chen HB, Wang Y, Liu Q, Zhang R, Jiang SW and Li J: Cytostatic and apoptotic effects of DNMT and HDAC inhibitors in endometrial cancer cells. Curr Pharm Des 20: 1881-1887, 2014.

16. Dowdy SC, Jiang S, Zhou XC, Hou X, Jin F, Podratz KC and Jiang SW: Histone deacetylase inhibitors and paclitaxel cause synergistic effects on apoptosis and microtubule stabilization in papillary serous endometrial cancer cells. Mol Cancer Ther 5: 2767-2776, 2006.

17. Yoshikawa M, Hishikawa KT and Fujita T: Inhibition of histone deacetylase activity suppresses epithelial-to-mesenchymal transition induced by TGF-betal in human renal epithelial cells. J Am Soc Nephrol 18: 58-65, 2007.

18. Xiao W, Chen X, Liu X, Luo L, Ye S and Liu Y: Trichostatin A, a histone deacetylase inhibitor, suppresses proliferation and epithelial-mesenchymal transition in retinal pigment epithelium cells. J Cell Mol Med 18: 646-655, 2014.

19. Aki K, Potter JJ, Michael C, Zhen D, Esteban M and Koteish AA: Histone deacetylase inhibition suppresses the transforming growth factor beta1-induced epithelial-to-mesenchymal transition in hepatocytes. Hepatology 52: 1033-1045, 2010.

20. Wang X, Xu J, Wang H, Wu L, Yuan W, Du J and Cai S: Trichostatin A, a histone deacetylase inhibitor, reverses epithelial-mesenchymal transition in colorectal cancer SW480 and prostate cancer PC 3 cells. Biochem Biophys Res Commun 456: 320-326, 2015

21. Livak KJ and Schmittgen TD: Analysis of relative gene expression data using real-time quantitative PCR and the 2(-Delta Delta C(T)) method. Methods 25: 402-408, 2001

22. Hao W, Wang HS, Zhou BH, Li CL, Zhang F, Wang XF, Zhang G, Bu XZ, Cai SH and Du J: Epithelial-mesenchymal transition (EMT) induced by TNF- $\alpha$ requires AKT/GSK-3 $\beta$-mediated stabilization of snail in colorectal cancer. PLoS One 8: e56664, 2013.

23. Gilles C, Newgreen DF, Sato H and Thompson EW: Matrix metalloproteases and epithelial-to-mesenchymal transition, 2005.

24. Faghihloo E, Akbari A, Adjaminezhad-Fard F and Mokhtari-Azad T: Transcriptional regulation of E-cadherin and oncoprotein E7 by valproic acid in HPV positive cell lines. Iran J Basic Med Sci 19: 601-607, 2016.

25. Thiery JP, Acloque H, Huang RY and Nieto MA: Epithelialmesenchymal transitions in development and disease. Cell 139: 871-890, 2009

26. Grzegrzolka J, Biala M, Wojtyra P, Kobierzycki C, Olbromski M, Gomulkiewicz A, Piotrowska A, Rys J, Podhorska-Okolow M and Dziegiel P: Expression of EMT Markers SLUG and TWIST in breast cancer. Anticancer Res 35: 3961-3968, 2015.

27. Shih JY and Yang PC: The EMT regulator SLUG and lung carcinogenesis. Carcinogenesis 32: 1299-1304, 2011.

28. Jing Y, Cui D, Guo W, Jiang J, Jiang B, Lu Y, Zhao W, Wang X, Jiang Q, Han B and Xia S: Activated androgen receptor promotes bladder cancer metastasis via SLUG mediated epithelial-mesenchymal transition. Cancer Lett 348: 135-145, 2014.

29. Li Y, Zhao Z, Xu C, Zhou Z, Zhu Z and You T: HMGA2 induces transcription factor SLUG expression to promote epithelial-to-mesenchymal transition and contributes to colon cancer progression. Cancer Lett 355: 130-140, 2014.
30. Liu YN, Abou-Kheir W, Yin JJ, Fang L, Hynes P, Casey O, Hu D, Wan Y, Seng V, Sheppard-Tillman H, et al: Critical and reciprocal regulation of KLF4 and SLUG in transforming growth factor $\beta$-initiated prostate cancer epithelial-mesenchymal transition. Mol Cell Biol 32: 941-953, 2012.

31. Wang W, Li X, Zhang W, Li W, Yi M, Yang J, Zeng Z, Colvin Wanshura LE, McCarthy JB, Fan S, et al: Oxidored-nitro domain containing protein 1 (NOR1) expression suppresses SLUG/vimentin but not snail in nasopharyngeal carcinoma: Inhibition of EMT in vitro and in vivo in mice. Cancer Lett 348: 109-118, 2014.

32. Lei W, Zhang K, Pan X, Hu Y, Wang D, Yuan X, Shu G and Song J: Histone deacetylase 1 is required for transforming growth factor- $\beta 1$-induced epithelial-mesenchymal transition. Int J Biochem Cell Biol 42: 1489-1497, 2010.

33. Noh H, Oh EY, Seo JY, Yu MR, Kim YO, Ha H and Lee HB: Histone deacetylase-2 is a key regulator of diabetes-and transforming growth factor- $\beta 1$-induced renal injury. Am J Physiol Renal Physiol 297: F729-F739, 2009.

34. Xiao W, Chen X, Liu X, Luo L, Ye S and Liu Y: Trichostatin $\mathrm{A}$, a histone deacetylase inhibitor, suppresses proliferation and epithelial-mesenchymal transition in retinal pigment epithelium cells. J Cell Mol Med 18: 646-655, 2014.

35. Mani SA, Guo W, Liao MJ, Eaton EN, Ayyanan A, Zhou AY, Brooks M, Reinhard F, Zhang CC, Shipitsin M, et al: The epithelial-mesenchymal transition generates cells with properties of stem cells. Cell 133: 704-715, 2008.

36. Knutson KL, Lu H, Stone B, Reiman JM, Behrens MD, Prosperi CM, Gad EA, Smorlesi A and Disis ML: Immunoediting of cancers may lead to epithelial to mesenchymal transition. J Immunol 177: 1526-1533, 2006.

37. Kudo-Saito C, Shirako H, Takeuchi T and Kawakami Y: Cancer metastasis is accelerated through immunosuppression during Snail-induced EMT of cancer cells. Cancer Cell 15: 195-206, 2009.

38. Ansieau S, Bastid J, Doreau A, Morel AP, Bouchet BP, Thomas C, Fauvet F, Puisieux I, Doglioni C, Piccinin S, et al: Induction of EMT by twist proteins as a collateral effect of tumor-promoting inactivation of premature senescence. Cancer Cell 14: 79-89, 2008.

39. Gal A, Sjoblom T, Fedorova L, Imreh S, Beug H and Moustakas A: Sustained TGF beta exposure suppresses Smad and non-Smad signalling in mammary epithelial cells, leading to EMT and inhibition of growth arrest and apoptosis. Oncogene 27: 1218-1230, 2008

40. Yongqing L, Shahenda EN, Darling DS, Yujiro H and Dean DC: Zeb1 links epithelial-mesenchymal transition and cellular senescence. Development 135: 579-588, 2008.

41. Yang AD, Fan F, Camp ER, van Buren G, Liu W, Somcio R, Gray MJ, Cheng H, Hoff PM and Ellis LM: Chronic oxaliplatin resistance induces epithelial-to-mesenchymal transition in colorectal cancer cell lines. Clin Cancer Res 12: 4147-4153, 2006.

42. Li QQ, Xu JD, Wang WJ, Cao XX, Chen Q, Tang F, Chen ZQ, Liu XP and Xu ZD: Twist1-mediated adriamycin-induced epithelial-mesenchymal transition relates to multidrug resistance and invasive potential in breast cancer cells. Clin Cancer Res 15: 2657-2665, 2009.

43. Cheng GZ, Joseph C, Qi W, Weizhou Z, Sun CD and Wang LH: Twist transcriptionally up-regulates AKT2 in breast cancer cells leading to increased migration, invasion and resistance to paclitaxel. Cancer Res 67: 1979-1987, 2007.

44. Kurrey NK, Jalgaonkar SP, Joglekar AV, Ghanate AD, Chaskar PD, Doiphode RY and Bapat SA: Snail and Slug mediate radioresistance and chemoresistance by antagonizing p53-mediated apoptosis and acquiring a stem-like phenotype in ovarian cancer cells. Stem Cells 27: 2059-2068, 2010.

45. Yang $H$, Zhang G, Che X and Yu S: Slug inhibition increases radiosensitivity of nasopharyngeal carcinoma cell line C666-1. Exp Ther Med 15: 3477-3482, 2018.

This work is licensed under a Creative Commons Attribution-NonCommercial-NoDerivatives 4.0 International (CC BY-NC-ND 4.0) License. 